Para enlazar con este artículo / To link to this article:

http://dx.doi.org/10.14198/fem.2019.34.05

Para citar este artículo / To cite this article:

Berger, Anne Emmanuelle. «Un nuevo cuerpo amoroso: escribir el cuerpo en tiempos del MLF». En Feminismo/s, 34 (diciembre 2019): 97-120. Dosier monográfico: Estado actual de la investigación en Literatura francesa y Género: balance y nuevas perspectivas / État présent de la recherche en Littérature française et Genre: bilan et nouvelles perspectives, coord. Ángeles Sirvent Ramos, DOI: 10.14198/fem.2019.34.05

\title{
UN NUEVO CUERPO AMOROSO: ESCRIBIR EL CUERPO EN TIEMPOS DEL MLF ${ }^{1}$
}

\section{A NEW AMOROUS BODY: WRITING THE BODY AT THE TIME OF THE (FRENCH) WOMEN'S LIB}

\author{
Anne Emmanuelle BERGER \\ Laboratoire d'Études de Genre et de Sexualité (LEGS) \\ UPL Université Paris 8 Vincennes Saint-Denis/ CNRS, París \\ aeb4@cornell.edu \\ orcid.org/0000-0002-9389-5784
}

\section{Resumen}

Considerando la escritura literaria producida en los años setenta por algunas de las mujeres que participaron en el Movimiento de Liberación de las Mujeres francés y, más concretamente, la manera en que algunos de estos textos celebraban, figuraban y desmantelaban el cuerpo y los cuerpos, planteo que, ya en ese momento, se estaba produciendo una desnormativización y una reconceptualización proto-queer del cuerpo en relación con el «sexo» y con la dualidad sexual, tanto en el plano político como en el estético. Una mirada rigurosa a la escritura de ese período cuestiona la opinión generalizada de que las escritoras de ese momento tendían a sostener una noción esencialista o naturalista de la escritura de las mujeres.

Palabras clave: literatura del Movimiento de Liberación de las Mujeres; cuerpo erógeno; cuerpo visceral; cuerpo insurgente; cuerpo trastornado; miradas de género.

1. Texto traducido del francés, a petición de la autora, por Soledad Soria Berrocosa.

Los contenidos de la revista se publican bajo una licencia de Creative Commons Reconocimiento 4.0 Internacional (CC BY 4.0)

Feminismo/s 34, diciembre 2019, pp. 97-120 


\begin{abstract}
Looking back at literary writings produced in the seventies by some of the women engaged in the French Women's liberation movement, and more specifically at the way the body and bodies were at once celebrated, figured and dismantled in a number of these texts, I argue that a proto-queer de-normativization and reconceptualization of the body with respect to «sex» and sexual duality was already at work at the time, on both a political and aesthetic level. A serious look back at the writings of that period challenges the widespread view that women writers of that time tended to hold on to an essentialist or naturalistic notion of women's writing.
\end{abstract}

Keywords: Women's lib literature; Erogenous body; Visceral body; Insurgent body; Deranged body; Gendered looks.

«Oh! nos os sont revêtus d'un nouveau corps amoureux !» (Rimbaud)

\title{
1. PRÓLOGO
}

Conocemos la célebre frase atribuida a Sigmund Freud por su biógrafo Ernest Jones. Durante una conversación con su amiga y discípula Marie Bonaparte, habría confesado a esta: «La gran pregunta que nunca ha obtenido respuesta y que hasta ahora no he sido capaz de contestar a pesar de mis treinta años de investigación del alma femenina, es esta: ¿Qué es lo que desea la mujer? ${ }^{2} \gg$ (Jones 2: 258). Freud confiesa así su fracaso para rendir cuenta del deseo femenino. Indescifrable porque reprimido, irreconocible por el síntoma histérico y la presión cultural, o rebelde a las expectativas masculinas, este deseo sigue siendo para él un «enigma». Ignoramos la respuesta de Marie Bonaparte a la pregunta de Freud, pero sí importa que esta haya sido dirigida a una mujer, como para invitarla a apropiársela en primera persona.

El acceso de las mujeres a la posición de sujeto de deseo constituye definitivamente un motivo central de su producción literaria en el siglo XX. Hoy, esta constatación perece banal. Si en parte se explica por la conquista progresiva, por parte de las mujeres, de la autonomía social y de toda clase de libertades nuevas en el siglo anterior, también conlleva la invención política, epistemológica y cultural del sujeto que desea, manifestación de la subjetividad

2. Traducido del inglés al castellano por Mario Carlisky y José Cano Tembleque.

Feminismo/s 34, diciembre 2019, pp. 97-120 
moderna de la que Foucault intentó hacer la genealogía de manera diversa en sus tres volúmenes de Histoire de la sexualité publicados en vida del autor. El psicoanálisis mismo ha desempeñado un papel fundamental en la invención del «sujeto que desea», haciendo del deseo, por primera vez en la historia del pensamiento occidental, un rasgo definitorio del sujeto y un elemento motor del proceso mismo de subjetivación.

A los relatos literarios sobre la resistencia que oponen las mujeres al deseo de los hombres por educación, escrúpulo religioso, prejuicio social o incluso por asco a la sexualidad masculina ordinaria -motivo claramente puesto de manifiesto por George Sand en Mauprat o por Renée Vivien en La Dame à la Louve-, ha sucedido así la afirmación sin rodeos de un deseo y de un goce polimorfos en femenino. Ya desde la primera década del siglo XX, la «force du désir» - es el título de una novela de Marie Krysinska publicada en 1905- se manifiesta en los escritos de mujeres. En una suerte de novela titulada Une femme et le désir, Valentine de Saint-Point dibuja un paralelo explícito entre el acto de «expresarse», cuya manifestación más relevante es la actividad literaria, y la actividad sexual. El siglo literario se abrió con Claudine à l'école, la primera novela moderna de educación para las niñas, publicada en 1900. Sin embargo, este relato de novillos no se centra tanto en el descubrimiento de la escuela y en los tesoros de la instrucción pública, recientemente accesible a las niñas, como en la feliz exploración de las emociones sexuales, ciertamente despertadas en el marco de una escuela abierta a la vida, lejos del núcleo familiar. Recordemos que esta exploración no hace ninguna distinción entre heterosexualidad y homosexualidad, y omite la frontera entre lo admisible y lo condenable. Tras un siglo XIX que rehace incansablemente el relato de la educación sentimental de todo joven, es pues la chica quien accede al rango de heroína en el siglo XX, otorgando así una especie de posteridad burguesa a La Princesse de Clèves. En la otra extremidad del siglo, Marguerite Duras seguirá, con L'Amant, el relato de la educación sensual en femenino. Y si cuando apareció Le Deuxième Sexe éste fue recibido como un manual de educación pornográfico ${ }^{3}$, es porque Beauvoir, siguiendo a Freud en esto, concede

3. François Mauriac arremete contra el libro en Le Figaro calificándolo de «manuel d'égoïsme érotique», y más precisamente de «effet causé sur un tempérament pas très solide par l'enseignement du bon docteur Freud». Marie-Louise Barron pronuncia

Feminismo/s 34, diciembre 2019, pp. 97-120 
a la expresión y a la exploración de la sexualidad un lugar preponderante en su descripción de la formación del sujeto «mujer».

Si ciertamente no ha habido respuesta unívoca y homogénea a la pregunta de Freud, podemos decir que los escritos de mujeres en el siglo XX constituyen, en varios aspectos, una respuesta a esta. Su nueva afirmación como sujetos de deseo ha permitido a las mujeres conquistar nuevos territorios literarios ${ }^{4}$. Por primera vez en Occidente ${ }^{5}$, se desarrolla una literatura erótica, incluso pornográfica, en femenino, que se formula en una relación compleja de imitación o al contrario de ruptura, si no resuelta, al menos deseada, con la literatura erótica producida por hombres. Otro rasgo importante: el lugar concedido a la experiencia homosexual. La homosexualidad no solo constituye un tema entre otros que da testimonio, por su insistencia, de la importancia de la sexualidad como categoría de la experiencia occidental moderna. La asociación claramente establecida entre el paso al acto homosexual y el paso al acto literario permite esclarecerlos mutuamente dando vía libre al desafío específico, para las mujeres, de su entrada en la literatura, según los términos que se plantea esta en el siglo del feminismo. Tanto si representa el amor hacia sí misma o hacia otra mujer, la inclinación homosexual corresponde a una posición libidinal activa, liberada de las restricciones y de las normas sociales, y, de ese modo, doblemente transgresora para las mujeres. Porque escribir es un acto, y lo que es más, un acto de exploración, que es aún percibido, por las mujeres del siglo XX, como un gesto de transgresión y de emancipación, como una suspensión de la prohibición de expresar el deseo (como deseo de expresión), similar al paso al acto homosexual. En el umbral del siglo, o incluso durante el gran momento del movimiento para la liberación de las mujeres, los círculos literarios femeninos y la formación de comunidades más o menos

opiniones similares en Les Lettres Françaises, y Jeannette Prenant, periodista comunista, propone colocar a Beauvoir dentro de «les suffragettes de la sexualité». Sobre la recepción de Le Deuxième Sexe en el momento de su publicación, ver Sylvie Chaperon.

4. El desarrollo que presentamos a continuación es fruto de un trabajo de investigación sobre la producción literaria de mujeres en el siglo XX llevado a cabo en colaboración con Marta Segarra. Me remito a los trabajos de esta última sobre la literatura erótica de mujeres, sobre la importancia del motivo homosexual en la literatura del siglo, y, finalmente, sobre el tratamiento del deseo en ella (Traces du désir).

5. Parece, por el contrario, que existe una tradición de literatura erótica en femenino muy antigua en Persia o incluso en Japón.

Feminismo/s 34, diciembre 2019, pp. 97-120 
explícitamente homosexuales coinciden así, al menos en parte. Finalmente, la tercera forma que presentó la nueva inscripción del deseo de las mujeres en literatura es la exploración de una gama de experiencias carnales que, al igual que la homosexualidad, pero sin limitarse a esta, sobrepasan el marco de la relación amorosa heterosexual con la cual la literatura occidental hacía hasta entonces su agosto. La segunda mitad del XX ha visto la emergencia de una especie de auto-erotismo en femenino, que muestra la conquista por parte de las mujeres de un cuerpo erogeneizado, que había sido amordazado o dormido durante largo tiempo. Ese «nuevo cuerpo amoroso», que Freud teorizó a partir de nociones como «pulsión», «libido»y «zonas erógenas», es un cuerpo vivido ${ }^{6}$, distinto del cuerpo objetivable de las tablas anatómicas. El cuerpo erogeneizado o cuerpo excitable sexualmente no es el cuerpo genérico, también llamado «biológico», que nos liga a la especie humana en tanto que especie animal. Tampoco es el cuerpo-naturaleza, es decir, literalmente, el cuerpo dado con y por el nacimiento -la palabra «naturaleza» significa literalmente lo que se refiere a lo «nativo»-. Es un cuerpo singular, conductor (al igual que hablaríamos de metal conductor de electricidad) o intérprete de fantasías conscientes o inconscientes, que guarda la memoria de las primeras caricias o de los primeros golpes recibidos, y que testimonia, llevando la huella o el estigma, la experiencia de cada sujeto en su dimensión histórica, a la vez, siempre, individual y colectiva. La cartografía de tal cuerpo es pues claramente imposible; inobjetivable, es, a un cierto nivel, infigurable. $\mathrm{Y}$ es este el objeto de nuestro estudio.

\section{ESCRIBIR EL CUERPO EN TIEMPOS DEL MLF}

Audrey Lasserre ha propuesto recientemente, de manera muy convincente y argumentada, leer el Mouvement de Libération des Femmes francés (MLF) como un movimiento literario (de manera que, añadiría, se podrían traducir las siglas MLF por 'Mouvement de Littérature des Femmes'), quizá incluso -afirma- el último movimiento literario de vanguardia del siglo $\mathrm{XX}^{7}$. De

6. Fórmula que utiliza Beauvoir en el capítulo de Le Deuxième Sexe que consagra al psicoanálisis y que ella misma tomó prestado de Maurice Merleau-Ponty.

7. Nos referimos a la tesis de Audrey Lasserre, titulada Histoire d'une littérature en mouvement : textes, écrivaines et collectifs éditoriaux du Mouvement de Libération des femmes en France (1970-1981).

Feminismo/s 34, diciembre 2019, pp. 97-120 
hecho, muchas autoras (con diferentes funciones: escritoras, pero también especialistas de literatura, editoras, etc.), tal y como subraya Lasserre, han jugado un papel capital dentro del Movimiento. De hecho, este ha suscitado el florecimiento de un gran número de escritos de mujeres, cuya multiplicidad, heterogeneidad, radicalidad y fuerza galvanizaron el Movimiento y marcaron la literatura, aunque, como lo muestran también los trabajos de Lasserre y de algunas otras, los historiadores de la literatura francesa en Francia hacen, en su gran mayoría, como si nada hubiese pasado, o muy poco.

Durante la década del MLF, la escritura del cuerpo se hizo explosiva, ya fuese para celebrar el cuerpo amoroso de las relaciones homosexuales (Wittig), los recursos de la masturbación (Cixous), la emoción de las reglas (Cardinal), el goce particular del alumbramiento (Leclerc) o incluso la maternidad en tanto que experiencia erótica en los confines de la vida y de la muerte (Chawaf) ${ }^{8}$. Eufórica o disfórica, angustiada o extática, la escritura se aventura, al menos, hacia la transcripción de un cuerpo erógeno en femenino (o más bien, côté femmes), una tarea jamás realizada hasta entonces.

En numerosos escritos literarios entre los más importantes de la década -al menos es la hipótesis que deseo sostener-, estaba en marcha algo así como un experimento proto-queer de «des-normativización», y más precisamente de des-figuración, de los cuerpos empíricos y, por consiguiente, de la idea de cuerpo $^{9}$. El acento puesto en la sexualidad, dentro de una perspectiva queer, ha abierto el camino a una reinvención performativa, a la vez especulativa y espectacular, del elemento o del medio de la experiencia sexual, siendo el cuerpo una reinvención siempre en proceso, y cuyas consecuencias políti-

8. Posteriormente, las escritoras se apoderarán de experiencias disfóricas que se convierten, por primera vez, en el objeto de una narración en primera persona del femenino, como la del aborto (Ernaux), la del incesto (Angot) o también la de la anorexia (Nothomb, De Vigan, Marzano).

9. Según Teresa de Lauretis, la primera en haber definido el proyecto y los contornos de una teoría queer en Estados Unidos, en 1991, pueden ser llamadas queer algunas «formas de resistencia a la homogeneización cultural» («forms of resistance to cultural homogenization»), y primeramente aquellas que emanan de algunas categorías de población designadas en su origen como queer, es decir sexualmente «desviadas» (1991 IV). Digamos, pues, que el vocablo queer sigue «siendo el nombre de una cierta manera de perturbar la heteronormatividad ( the name of a certain unsettling in relation to heteronormativity»), tomando prestada, esta vez, la fórmula de otra teórica queer estadounidense, Carla Freccero. 
cas y culturales no han sido todavía plenamente evaluadas. Sin embargo, en cuanto hablamos, como lo he hecho yo misma, de «corps érogène», o, como dijo Rimbaud, de «corps amoureux», se trata en efecto de una concepción de la sexualidad y de la experiencia sexual (en el sentido freudiano, es decir no genital, de estas últimas). Y esta concepción arrastra necesariamente en su desarrollo la cuestión del binarismo sexual. Lejos de señalar una creencia atávica en la naturalidad de la dualidad sexual o en lo que se consideraría como tal, lejos sobre todo de poner de relieve necesariamente un anclaje de las reivindicaciones de las mujeres en la «biología», como se ha pretendido a menudo, el acento puesto sobre el «cuerpo» por parte de ciertas escritoras de la década MLF, y el tratamiento explosivo de este último, a la vez exaltado y «decapante», pueden ser leídos así como una anticipación de la deconstrucción queer del cuerpo, de su «naturaleza», de sus placeres, y de su potencial transformatorio.

\section{EL CUERPO VISCERAL}

En 1973 se publica Le corps lesbien de Monique Wittig. A la vez canto sáfico y exploración quirúrgica del «cuerpo amoroso» lésbico, Le corps lesbien rompe de varias maneras con la tradición literaria occidental de la celebración del cuerpo amado. Contraviniendo la gran tradición lírica, el texto refuta la oposición funcional del o de la amante y de la amada, del sujeto y del objeto del discurso amoroso. Incluso si el halago se dirige con insistencia a un-a «tú»o un-a «a ti» adorado-a, la destinataria e inspiradora del canto figura también como una agente del discurso tanto como de la penetración erótica del cuerpo. Colabora en la descripción de este último al igual que su amante:

M/on clitoris l'ensemble de m/es lèvres sont touchés par tes mains. A travers $\mathrm{m}$ /on vagin et $\mathrm{m}$ /on utérus tu t'introduis jusqu'à m/es intestins en crevant la membrane. Tu mets autour de mon cou mon duodénum rose pâle assez veiné de bleu. Tu déroules $\mathrm{m} / \mathrm{on}$ intestin grêle jaune. Ce faisant tu parles de l'odeur de m/es organes mouillés, tu parles de leur consistance, tu parles de leurs mouvements, tu parles de leur température. (33) [la cursiva es mía]

El corte gráfico sistemático del determinante posesivo y del pronombre personal en primera persona atenta literalmente contra la integridad del sujeto de la enunciación, y, por consiguiente, contra su soberanía simbólica. La 
escisión experimental del sujeto operada por Wittig duplica y repite el trabajo de disección del cuerpo, a la vez minucioso y violento, sin que haya una voluntad de hacer daño. Finalmente, y sobre todo, ya no se trata de componer aquí un blasón anatómico, idealizado o burlesco, de tal o cual parte visible del cuerpo, sino de cartografiar con precisión un viaje al centro del cuerpo, sin preocuparse de delimitar la belleza y la fealdad, lo agradable y lo abyecto.

Es esta primacía otorgada al cuerpo interior o visceral lo que caracteriza a las escrituras del cuerpo de esta época, las de, en primer lugar, Cixous, Chawaf, Hyvrard, Wittig, pero también las de Leclerc o incluso las de Forrester, sea cual sea la erótica, incluso la política que sustentan el viaje de exploración. El mismo año de la publicación de Le corps lesbien, Marguerite Duras declaraba durante una entrevista con Suzanne Horer y Jeanne Socquet: «Si la femme se prive de son être organique, on peut dire: de sa nuit organique, elle deviendra un homme. C'est là un danger, c'est plagiaire» (186-187). Y añade un poco más lejos: «Toutes les expériences organiques sont miraculeuses. L'expérience érotique comme l'expérience de la maternité, comme l'expérience d'un soulèvement révolutionnaire» (187). Wittig no contaría, ciertamente, la «experiencia orgánica»-y erótica- de la maternidad entre los «milagros» con los que algunas mujeres, como Duras, pretendían hacer su materia o su masa literaria. Sin embargo, Duras y Wittig coinciden en designar una cierta «noche orgánica»-la «noche orgánica» que sugiere zambullirse en las profundidades del cuerpo- a la vez como fuente de inspiración y como nuevo territorio de escritura.

Un año más tarde, en 1974, Annie Leclerc definía así «le bonheur de vivre» en Parole de femme: «Moi je voulais d'abord le bonheur de vivre, [...] le bonheur d'aimer ce que je toucherais, verrais, entendrais, mangerais, éprouverais dans tout mon corps de femme, parce que je voulais aimer, toucher, voir, entendre, manger et vivre mon corps dans son propre bonheur de vivre» (46). Y resalta dos páginas más adelante: «Vivre est heureux. Voir, entendre, toucher, boire, manger, uriner, déféquer, se plonger dans l'eau et regarder le ciel, rire et pleurer, parler à ceux qu'on aime, et mêler son corps à leur corps est heureux» (48).

Si aquí se trata menos de escribir que de «vivir», el gozo de vivir no deja de ser el tema, la meta de esa "palabra de mujer». Y este no pasa primero por la satisfacción sentimental proporcionada por una pareja, un-a amante o un

Feminismo/s 34, diciembre 2019, pp. 97-120 
niño, sino por la experiencia auto-erótica de una plenitud corporal libremente experimentada que traduce la lista de los infinitivos intransitivos -«ver, oír, tocar, beber, comer, orinar, defecar, sumergirse en el agua»-antes que toda mención a un cuerpo-a-cuerpo amoroso.

Un año más tarde aparece Cercœur de Chantal Chawaf. En la misma línea que Colette, pero sin la ligereza pícara de esta, Cercœur convoca todas las materias y las sensaciones físicas, e inventa el lenguaje de su entrelazamiento:

J'adhère à la verdure de la terre, Verdurette! Verduron! à la patouillerie, à la pâte de la terre délayée, réduite en bouillie, qui me colle, me pâte aux pieds, m'afroidille, me fait patouiller, m'enfonce dans la patouille, dans la mouille jusqu'aux genoux. Une vieille femme, sous l'arbre du pré, est en train d'abattre les noix à coups de perche. Tu patauges avec plaisir, Verdurette! Verduron! «floc! floc!» dans les flaches, dans la terre criblée d'eau froide. «Bé! dépêche-toi! » Ça pleut. Ça brouillasse. Ça vente. Le vent tourbillonne.

La invención léxica, la repetición hechicera y el «revuelo» paronomástico de los significantes llevan a cabo la fusión de las materias, de los estados y de las funciones del cuerpo, del exterior y del interior, de lo oral y de lo anal, del ruido y de la palabra, del lenguaje infantil y del lenguaje maternal, sumergiendo efectos y atmosferas, lugares y personajes en el caldero metabólico de la escritura.

En Souffles, igualmente publicado en 1975, Hélène Cixous confirma también «n'en vouloir à aucune visible et nue partie» del cuerpo deseado:

- s'ouvre avec si tendre et tremblante élasticité, enfin, se débat, lentement s'efface, $[\ldots]$ s'ouvre parce que j'en crève de désir, ton anus, $-[\ldots]$ - ce n'est pas à son ventre que j'en ai voulu, je n'en veux ni à ses seins, ni à ses cuisses moelleuses, ni à aucune visible et nue partie, mais au secret du ventre, aux viscères, à ce qui la remplit, aux organes qui l'agissent, furieusement à ses replis, à ses sources, aux rouages secrets qui animent cette très haute puissance [...]. (69) [la cursiva es mía]

Confundiendo ano y vagina en la evocación alucinada de un trabajo de alumbramiento por un «ser de belleza» de género incierto, como el «Being Beauteous» rimbaudiano, la narradora en trance da aquí consistencia literaria a esas teorías de cloaca de la que habla Freud cuando evoca las especulaciones infantiles relativas al nacimiento de los hijos. Aquí de nuevo, el cuerpo exaltado, en el cual se anula toda distinción entre cuerpo propio y cuerpo

Feminismo/s 34, diciembre 2019, pp. 97-120 
extranjero, es un cuerpo visceral del que el texto explora con delicia los pliegues internos, sustituyendo al relato de una salida de un cuerpo de niño-a, que todas las metáforas del «trabajo» y del «término» se hacían oír desde hace varias páginas, la descripción increíble de un regreso al «cuerpo adorado» de esta «madre de belleza», la cual puede ser, como su prototipo rimbaudiano, amante, macho o hembra ${ }^{10}$.

Vestiges, jirones de una narración en dos lenguas (francés e inglés) escrita en primera persona del masculino por Viviane Forrester, y publicada en 1978, gira también en torno a un cuerpo materno. Pero en este caso se trata de un cuerpo odiado, cuya descomposición y abyecta sexualidad describe el narrador, hijo enfurecido:

Comment détester plus? Suinter. Mais que, du texte à la chair lente et chaude, je ne puisse moi non plus, cette sueur-là, ce matin-là, toucher ! se retournait en nage (larmes). [...] Oh maman, je n'aurai pas d'histoire. Mais elle, soudée à ces réseaux de nerfs lentement arrachés au gré du phallus, de l'anus, des cuisses d'Anthony Cross [...] (55)

E incluso: «Létang rougi de sang, menstrues de ma mère, odeurs de volcans, de vomi, glaires mâles, et l'espace suinte» (58).

Siguiendo en esa vena (o ese intestino), Jeanne Hyvrard ofrecerá en la entrada «Littérature» de La Pensée Corps, en 1989, una especie de clave de lectura retrospectiva de este diálogo de la literatura con los canales secretos del cuerpo, practicado entonces por un gran número de escritoras. En este diccionario fantástico, ella define, en efecto, «la literatura» como un «long canal pour parvenir au jour» (128). La travesía del «canal», en que consiste la gesta «literaria», se efectúa gracias a la utilización de una «langue du marais» ${ }^{11}$ (128), lengua acuosa si no pringosa porque arrastra las materias transportadas por ese canal que la escritora califica por otra parte de «égout». En el artículo «Canal», leemos en efecto: «Tes mains de, bitume enserrant

10. Así decía Arthur Rimbaud en «Being Beauteous»: «Devant une neige un Être de Beauté de haute taille. Des sifflements de mort et des cercles de musique sourde font monter, s'élargir et trembler comme un spectre ce corps adoré ; des blessures écarlates et noires éclatent dans les chairs superbes. [...] Et les frissons s'élèvent et grondent, et la saveur forcenée de ces effets se chargeant avec les sifflements mortels et les rauques musiques que le monde $[\ldots]$ lance sur notre mère de beauté $[\ldots]$ ».

11. «Je ne peux sans la langue du marais dire la pensée-corps [...]».

Feminismo/s 34, diciembre 2019, pp. 97-120 
mes eaux d'amour. Ce long égout me conduisant vers le jour. Dans le ventre terrestre, le voyage est sans fin» (28).

\section{EL CUERPO SUBLEVADO}

Hay que poner en relación, sin duda, esta atención sin precedente que conceden las escritoras a las sensaciones del cuerpo y de sus cuerpos con la sublevación de las mujeres durante la década del MLF. Es lo que sugiere Duras cuando subraya la homología de dos «experiencias» que dan cuenta, según ella, de un mismo «miracle organique»: «l'expérience érotique» y «l'expérience d'un soulèvement révolutionnaire». Como sabemos, lo que distingue el movimiento de las mujeres durante aquellos años, a diferencia de otros periodos, anteriores o posteriores, de expresión pública de reivindicaciones feministas, no es solo su amplitud, sino también el acento puesto sobre la doble cuestión de la sexualidad y de los derechos de las mujeres a disponer libremente de su cuerpo. Cixous vincula, explícitamente y en varias ocasiones, en Le Rire de la Méduse, texto-manifiesto publicado en el momento álgido de la lucha de las mujeres de aquella época, la cuestión de la «venida» de las mujeres a la escritura, así como la de la liberación de los cuerpos. Ambas cuestiones, escritura y cuerpo, ya desde el primer párrafo del ensayo, se encuentran ligadas en una misma afirmación: «Il faut que la femme s'écrive: que la femme écrive de la femme et fasse venir les femmes à l'écriture, dont elles ont été éloignées aussi violemment qu'elles l'ont été de leurs corps; pour les mêmes raisons, par la même loi, dans le même but mortel» (37) [la cursiva es mía]. Más adelante, Cixous llama a las mujeres o a «la femme» a la revuelta en estos términos: «Ecris-toi: il faut que ton corps se fasse entendre». Y argumenta: «Une femme sans corps, une muette, une aveugle, ne peut pas être une bonne combattante» (46). Sin embargo, nos equivocaríamos viendo en este desencadenamiento literario del cuerpo un fenómeno exclusivo de los escritos de mujeres de aquella época. Sus contemporáneos masculinos no se quedan atrás, aunque sea, sobre todo, desde la vertiente de la filosofía como se escribe, en una enunciación masculina, la insurrección del cuerpo y de los cuerpos ${ }^{12}$. Hay que decir que

12. Evidentemente, podemos, en cuanto a la literatura, pensar en Pierre Guyotat, cuyas obras Eden, Eden, Eden (1970) y Prostitution (1975) demuestran un mismo desencadenamiento libidinal y textual.

Feminismo/s 34, diciembre 2019, pp. 97-120 
la filosofía francesa de esa época se imbrica con la experiencia literaria, cosa insólita hasta entonces -exceptuando el Siglo denominado «de las Luces»-en la historia del pensamiento occidental. ¿Quién no conoce la declaración de Michel Foucault, en el primer volumen de su Histoire de la sexualité, invitando a «faire valoir» «les corps, les plaisirs, les savoirs, dans leur multiplicité et leur possibilité de résistance», «contre les prises du pouvoir» (208)? En cuanto a la convergencia entre el comienzo de Économie libidinale, -ensayo de Jean-François Lyotard publicado en 1974 sobre la economía política del cuerpo erógeno postfreudiano durante el régimen capitalista- y las primeras páginas del Corps lesbien, es más que llamativa.

J/e découvre que ta peau peut être enlevée délicatement pellicule par pellicule, $\mathrm{j} / \mathrm{e}$ tire, elle se relève, elle s'enroule par-dessus tes genoux, [...], elle glisse le long du ventre, à partir des reins j/e tire, la peau découvre les muscles ronds et les trapèzes du dos [...], je découvre la beauté de l'os brillant parcouru de vaisseaux sanguins (Wittig 9)

escribe la celebrante del cuerpo lesbiano entregándose a un desuello minucioso que viene a prolongar una delicada autopsia del cuerpo vivo de su amante. Por su lado, Lyotard también se empeña en rajar «la grande pellicule éphémère» (es el título del primer capítulo de Économie libidinale) de un cuerpo que solo aparece como femenino en el momento del desgarre de su envoltura exterior, en unos términos que están en armonía con la labor quirúrgica de Wittig:

Ouvrez le prétendu corps et déployez toutes ses surfaces: non seulement la peau avec chacun de ses plis, rides, cicatrices, avec ses grands plans veloutés [...], mais ouvrez et étalez, explicitez les grandes lèvres, [...] dilatez le diaphragme du sphincter anal, coupez longitudinalement et mettez à plat le noir conduit du rectum, puis du côlon [...], donnez jour au prétendu intérieur de l'intestin grêle, [...] au duodenum [...]. (9)

En la página siguiente, Lyotard ofrece el comentario filosófico de su gesto inaugural:

Ce n'est pas ce déplacement de parties, reconnaissables dans l'économie politique du corps organique (lui-même d'abord agencé de parties différenciées et appropriées, celles-ci n'allant pas sans celui-là) qu'il faut commencer à prendre en considération. Il ne faut pas commencer par la transgression, il faut aller tout de suite jusqu'au bout de la cruauté, faire l'anatomie de la

Feminismo/s 34, diciembre 2019, pp. 97-120 
perversion polymorphe, déployer l'immense membrane du 'corps' libidinal, toute à l'inverse d'une membrure. Elle est faite des textures les plus hétérogènes, os, épithéliums, feuilles à écrire, airs à faire vibrer [...]. Toutes ces zones sont aboutées en une bande sans vers, bande de Moebius [...]. La bande interminable à géométrie variable (car rien n'oblige à ce qu'une excavation reste concavité outre qu'elle est forcément convexité au 'deuxième' tour $[\ldots]$ ) n'a pas deux faces mais une seule face, et donc pas d'extérieur ni d'intérieur. (10)

Reconocemos, en este poner en tela de juicio la disposición de las partes del cuerpo en un todo organizado, funcional e identificable, y en el elogio del valor heurístico, y de la fuerza de conmoción, de una cierta «cruauté» desprovista de sadismo, el eco prolongado de la insurrección de Antoine Artaud en contra de «les cadres de notre actuelle anatomie.» (219). Si Lyotard lee y cita a George Bataille o al Marqués de Sade, al igual que Jacques Lacan, Jacques Derrida y Maurice Blanchot en la misma época, si se interesa, como otros, por la erótica literaria de Pierre Klossovski, es sobre todo a Artaud a quien debe, al igual que su contemporáneo Gilles Deleuze, la posibilidad de pensar un «corps sans organes», es decir, un cuerpo inorganizado o desorganicizado, sin partes ordenadas las unas a las otras según tal ley de la cultura declarada como ley de la naturaleza. Podríamos, también, poner en relación la impugnación hecha por Lyotard de la topología clásica que separa, distingue y opone dentro y fuera, obligando al pensamiento del cuerpo a entrar en los marcos conceptuales restrictivos de la «anatomía»-recordemos que el término «anatomía» designa literalmente el corte analítico del cuerpo en partes identificables porque distintas (el cuerpo «anatomizado» es pues un cuerpo muerto) - con el trabajo que hace en el mismo momento Jacques Derrida sobre «la double invagination conceptuelle des bords» (La Vérité en peinture; Parages), otra versión de la cinta de Moebius con la que juega el filósofo.

Cixous prefiere la «saveur forcenée» de un nuevo cuerpo amoroso soñado por Rimbaud a las liturgias pornográficas de Bataille o de Klossovski. Sin embargo, ella es, en aquel momento, una lectora de Artaud. Releer esta insurrección generalizada de los cuerpos escritos a la luz del legado de Artaud ${ }^{13}$

13. Recordemos que una revista con vocación interdisciplinar titulada Corps écrits fue creada en 1982 por Béatrice Didier, universitaria y crítica literaria feminista, como eco a la inscripción inédita del cuerpo y de los cuerpos en los textos literarios y filosóficos,

Feminismo/s 34, diciembre 2019, pp. 97-120 
permite, quizás, observar desde otra perspectiva la «querella del sexo» que se articuló en torno a la noción de «écriture féminine» como escritura del cuerpo, desde la invención de esta última por Cixous.

\section{EL CUERPO DES-GENERIZADO}

Se ha leído a menudo Le Rire de la Méduse y Sorties, otro texto de Cixous publicado el mismo año y que sigue la reflexión iniciada en Le Rire sobre el sentido y la necesidad de «l'écriture féminine», en tanto que escritos esencialistas, e incluso diferencialistas, que ejercerían una doble reducción de las mujeres a su cuerpo y de su cuerpo, a su sexo, concebido como órgano de su identidad y signo de su diferencia. ¿No califica Cixous «les vrais textes de femmes» de «textes avec des sexes de femmes»? (Le Rire 40) ¿No invita a las mujeres a hacer temblar a los sacerdotes del orden androcéntrico, enseñándoles sus «sextos», en la estirpe de la Gorgona y de Baubo (54)?

En una reseña de Souffles, publicada el mismo año de su aparición en la revista feminista francófona Les Cahiers du GRIF, Marie Denis ${ }^{14}$, escritora belga y colaboradora asidua de esos mismos Cahiers durante la década del MLF, reprocha por su parte a Cixous usar el término «coño» en repetidas ocasiones. En ello ve la suscripción fácil a una «mode»; la del «parler argotique mâle» de «l'intellectuel gauchiste parisien». Cixous pensaría equivocadamente, sigue diciendo Denis, que ese «bête mot» «avec lequel ils nous tiennent humiliées» podía ser utilizado por las mujeres (dándole la vuelta al estigma, como se dice hoy en día) para representar su nueva «liberté de parole» (1975 9-1:103-105). Finalmente, podríamos añadir que, no contenta con llamar la atención sobre el propio sexo femenino, la evocación del «coño» da cuenta en general de una fantasmática sexual heteronormativa muy clásica. ¡Cuántos «coños» en Georges Bataille, sin hablar del célebre Con d'Irène de Louis Aragon! Sin embargo, un «coño» puede cambiar de sentido cuando varía su uso y su localización corporal. Precisamente, para Artaud, el «coño» no es un órgano femenino devaluado, sino una zona de intensidad del cuerpo

característica de la década anterior. La revista, en su momento importante, dejó de ser publicada en 1990.

14. Su verdadero nombre es Éliane Stas de Richelle. Marie Denis nació en Lieja el 4 de diciembre de 1920, y falleció en Ixelles el 30 de julio de 2006.

Feminismo/s 34, diciembre 2019, pp. 97-120 
alucinado del «Mômo». Aunque sigue cargado de connotaciones sexuales, ya no es, estrictamente hablando «sexuante», en el sentido de que evidenciaría una pertenencia de sexo, como tampoco estaría al servicio de una sexualidad copulativa y normativa. Imposible deducir de su mención, incluso de la reivindicación de su posesión por Artaud, el género ni tampoco el sexo del autor $^{15}$. Volviendo a Cixous, varios indicios invitan a hacer una lectura más «artaudiana» que «bataillana» del deslizamiento metonímico que opera del cuerpo al sexo, o a la inversa, en los textos de aquellos años.

Souffles apareció el mismo año que Le Rire de la Méduse y Sorties. Podríamos pensar que el soplo que la anima es el mismo que el que dicta a Cixous su llamada a «inscrire le souffle de la femme entière» (Le Rire 46), y que Souffles se convierte así en la mejor ilustración -al lado de las obras de Shakespeare, de Kleist y de Genet citadas entonces por Cixous como ejemplos de «escritura femenina»- de esta «escritura» a la cual la escritora desea dar cuerpo. No obstante, ya lo he dicho, el cuerpo explorado y exaltado en Souffles es sobre todo un cuerpo interior, vivo y cambiante, al cual es difícil por ello asignar una identidad o un género, donde el género -entendido aquí como marcador de identidad y operador de asignación a una categoría en el seno de un orden sexual binario- tiene que ver con características o atributos identificables por visibles, por lo tanto con la percepción externa del cuerpo, y más precisamente con las modalidades culturales y las condiciones sociales de regulación de esta percepción. Plantándose delante del «Être de Beauté» de la Iluminación rimbaudiana «Being Beauteous» que constituye a la vez una matriz de escritura y uno de los principales intertextos de Souffles, la «souffleuse» (o la «soufflée») del texto se pregunta, de hecho: «Est-ce que c'est une femme?» (38). El «Être de Beauté de haute taille», cuyas «chairs superbes» están agujereadas con «blessures écarlates et noires» cambia en efecto de género durante el transcurso de la evocación para convertirse, al final de la iluminación, en «notre mère de beauté» (hablo aquí de la Iluminación de Rimbaud). La respuesta de Cixous a su propia pregunta, que une el gesto al

15. «dieu / s'est mis sur le poète, / pour lui saccager l'ingestion/ de ses vers, / tels des pets de tête / qu'il lui soutire par le con, [...] Et si on ne comprend pas l'image, / [...] qui est au fond de mon trou de con,-// c'est que vous ignorez le fond, / non pas des choses, / mais de mon con/ à moi $[\ldots] »(16)$. 
enunciado suprimiendo el pronombre personal que revelaría de antemano el género del ser en cuestión: «-Est plus qu'une femme. N'est pas une nonfemme-» (38). Y se explica en la página siguiente:

Que ça s'appelle femme est une ruse de poète. Façon de rabattre un passé sur l'insoutenable vision. [...] Elle est sortie. [...] Loin derrière nous les mondes râlent. Elle est. A l'exclusion de tout lien humain. Faim nue. Exclusivement corps pour Sa Vengeance. Chair. Rouge et noire. Vengeance. Pain de faim. (39)

La palabra «mujer» es, por lo tanto, un paleónimo, una palabra antigua olvidada y desterritorializada que sirve para designar, no el antiguo estado de la división sexual, sino una visión nueva que es diferente o más que humana ${ }^{16}$. Del mismo modo, podríamos decir que Souffles intenta arrancar el término «coño», al igual que el término «sexo», a sus contextos, sus usos y sus significaciones habituales, desafiando el orden indisociablemente simbólico y social que rige sus usos. Quedan, o más bien emergen, gracias a esta «salida» poética del círculo o de los «cadres de notre actuelle anatomie»-«Elle est sortie. [...] Loin derrière nous les mondes râlent»-, los destellos pre o posthistóricos de la carne : "Chair et souffle préhistorique, ici nous sommes entre vivants sauvages» (68), se complace en decir Cixous, quien incluye dentro de esos «vivants sauvages», tras la huella de Rimbaud, «femmes, nègres, volants» $\mathrm{O}$ también «enfants» (167).

Tenemos aquí, sin duda, un texto que cree o quiere creer en la liberación de los «vivants» de cualquier género, y que, además, la canta. En cambio, Foucault, al menos si tenemos en cuenta y nos ceñimos a la frase que cierra La Volonté de savoir, no cree en ello y alerta sobre la ilusión ingenua que consiste en pensar que se puede, gracias a «la force du désir», escapar a las garras del poder ${ }^{17}$. Sin embargo, el Foucault de 1976, al igual que la Cixous de 1975, exalta «les corps et les plaisirs» que convierte en el «point d'appui de la contre-attaque» contra «les prises du pouvoir» (208).

16. Sobre la restricción y los recursos de la paleonimia como nuevo uso de un léxico antiguo, ver Jacques Derrida, Positions y Marges De la philosophie.

17. «Ironie de ce dispositif [NB : se trata del dispositivo de sexualidad]: il nous fait croire qu'il y va de notre 'libération'» (211).

Feminismo/s 34, diciembre 2019, pp. 97-120 
A pesar de que Cixous permanece fiel a sus ideas y a su escritura, a una concepción de la sexualidad o de lo sexual que podemos calificar de freudiana, se dedica no obstante, al igual que Foucault, a denunciar «l'instance du sexe» como ordenadora de identidades fijas y homogéneas, como la representante de una política anatómica y productora de una anatomía política que ella misma impugna, a semejanza de otras mujeres comprometidas con el Movimiento de mujeres de aquella época. Mientras que Foucault evoca a pesar de todo (incluso si no cree en ello) la posibilidad de una «autre économie des corps et des plaisirs» para acabar con «l'austère monarchie du sexe» (211), Cixous se insurge contra la «monarchisation du désir» que engendra un «corps (anatomie politique) centralisé, sous la dictature des parties» (Le Rire 60). Cada uno en su lengua sueña así en el mismo momento con cuerpos capaces de sacudir las cadenas de un sexo-monarca.

Pese a que Marie Denis recriminó a Cixous la utilización del término «coño» en Souffles, no por ello dejó de elogiar con entusiasmo este texto que escapa a todo género. En esa misma reseña efectuaba una asociación entre Cixous y Wittig, declarando ver en la obra de una y otra, sin por ello «confundirlas» [sic], a las dos madres literarias de la belleza insurrecta del Movimiento de las mujeres. (Una «madre de belleza», lo hemos vislumbrado el tiempo de una Iluminación, no posee necesariamente un género, ni incluso un sexo, femenino). «Il m'arrive», escribía Denis en aquella ocasión, «de nouer Monique Wittig et Hélène Cixous, comme les deux coques du ruban qui nous lient toutes ensemble» (105). Para esta lectora apasionadamente implicada en la lucha de las mujeres, tanto los textos de Cixous como los de Wittig se encuentran comprometidos en un mismo combate contra la «dictadura de las partes», cuando estas figuran o son consideradas como un todo, cuando centralizan el placer y rigen la organización de la identidad. Más aún, para ella, ambos textos ríen o gozan precisamente de liberarse, o, liberándose, del etiquetado de lo que llamamos hoy género.

La psicoanalista Michèle Montrelay, una de las primeras en haber proporcionado «en caliente» una reflexión sobre el sentido y las modalidades de la expresión literaria de un cierto número de mujeres en esa época, advirtió en L'Ombre et le nom que sus textos «désamorçaient le désir», suscitando en su lugar goce... o repulsión. Atribuía esto al trabajo de demolición o de abolición de la imagen del cuerpo efectuado en diversas obras como las de Hyvrard, 
Chawaf o incluso Cixous y Wittig en aras de una escritura de las «sensations», término que encontramos además en la pluma de Foucault luchando contra el régimen monárquico del sexo: «Le lecteur masculin», escribe Montrelay, que se identifica de cierta manera con este,

est mis en présence d'une féminité qui n'est pas la sienne. Vocalisée, chantée, criée, elle ne trace aucun contour sur lequel l'œil pourrait s'arrêter. Ni visible ni voilée. Rien qui excite la curiosité. Le désir est désamorcé.

Faute d'images, beaucoup de femmes aussi se détournent, privées d'un miroir. Ces livres baignent en effet dans une sorte archaïque, non spéculaire, de narcissisme.

Mais ils sont là. [...] On se retrouve dans ces textes dans un élément où les sensations, les pensées, se déplient, s'ouvrent, s'épanouissent, et vous précèdent désormais.

Textes-jouissance, en perpétuelle extension. (153) [la cursiva es mía]

Trasladados, como unas Alicias de una especie no identificable, al otro lado del espejo, donde ya no se distingue ninguna forma reconocible, esos textos arremeten contra el edificio del género, o más bien impiden a este fijarse, como ya lo he dicho, ahí donde se apoya para orientar el deseo, sobre la regulación, normativa o ideal, de la imagen del cuerpo.

\section{EPÍLOGO}

Recientemente, la teórica feminista británica Clare Hemmings se consternó al ver el crédito que se otorga hoy a un cierto discurso mantenido en los círculos feministas y postfeministas; un discurso según el cual las feministas de la segunda generación y sus herederas quedarían sumidas en una visión heteronormativa de la sexualidad y de los placeres del cuerpo, a diferencia de las feministas y postfeministas queer, quienes serían las únicas que «gozarían realmente» (would have all the fun) (79-102). La formación y la difusión de tal discurso me parecen ser la consecuencia de las «sexwars» (guerras del sexo) que han enfrentado en los Estados Unidos, durante la década de los ochenta, a las feministas anti-pornografía (pero también anti-prostitución y anti-acoso sexual, como Catherine McKinnon), con las feministas pro-pornografía, en su mayoría lesbianas, proclamándose ellas mismas, en respuesta a lo que percibían como un puritanismo feminista lleno de resabios conservadores, «pro-sex» o «sex-positive». Esta «guerra» ha dejado cicatrices teóricas

Feminismo/s 34, diciembre 2019, pp. 97-120 
y políticas. Como bien sabemos, esta ha llevado a numerosas feministas «prosex» a guardar distancias con un feminismo percibido como represivo y normativo, y ha abierto el camino a la creación de estudios de sexualidad (es decir, estudios gais y lesbianos que se presentan propiamente como estudios de sexualidad) -creación también precipitada por el trato público moralizador y discriminatorio de la crisis del sida en Estados Unidos-, en un gesto de escisión asumida con respecto a los estudios de género. A su vez, la apertura de este ámbito ha favorecido la emergencia del pensamiento queer y, en la estela de su elaboración, el giro queer del feminismo occidental. La historia política y teórica del feminismo norteamericano ha desempeñado, y sigue desempeñando, en efecto, un papel significativo en la evolución del feminismo, definiendo los términos y los virajes, al menos en el área occidental. Y, sin embargo, si examinamos de cerca los textos de la década del MLF, e incluso los que no mostraban ninguna ambición literaria propiamente dicha, parece difícil mantener la idea de que la segunda ola del feminismo era tan aburrida (dull) como normativa. No intento aquí borrar las divergencias políticas y estratégicas, a veces profundas, a veces contingentes -influyendo las alianzas personales, las amistades o las enemistades, en la lectura de las acciones, de los acontecimientos y de las posturas tomadas- de las pensadoras, e incluso de los pensadores, de la época del MLF, ni tampoco las especificidades estéticas y las particularidades idiomáticas de las obras mencionadas. Pero me parece que había efectivamente algo en común en una cierta revuelta literaria contra el cuerpo naturalizado del heteropatriarcado, revuelta alimentada por la lectura de Rimbaud -poeta queer avant la lettre-y para Cixous, y para muchos otros, por un redescubrimiento apasionado de Artaud.

Aun así, es cierto, el «goce», hasta entonces insólito, articulado en esos textos, no corresponde a la definición actual de lo que entendemos, o incluso a lo que debe entenderse, por goce o más bien placer(-es) queer, queer fun. Soy consciente de que las-los activistas, incluso las-los teóricas-os queer de este principio del siglo XXI -hablo de aquellas y aquellos, cada vez menos numerosos, que se interesan todavía por la literatura en lengua francesa-, son más susceptibles de recurrir a Virginie Despentes, quien recibió en 2011 un premio LGBT (the Lambda Literary Award) por su ensayo King Kong Théorie, que a Cixous o incluso a Wittig. Sin duda hay en ello una dinámica generacional. Pero existe también algo más. Según la lectura que acabo de proponer, las

Feminismo/s 34, diciembre 2019, pp. 97-120 
obras de las que hablo, o al menos algunas de ellas, contribuirían a demoler las bases del edificio del género (en tanto que sistema de bicategorización jerarquizante), desviando la atención de la imagen del cuerpo, y por lo tanto también de los mecanismos de producción de apariencias normativas o de morfologías ideales, en cuya configuración, fijación y percepción colaboran toda clase de procesos sociales y psíquicos (o psiquizados). Pienso, por ejemplo (y los enumero sin orden), en las formas de mimetismo inconsciente socialmente inducidas, en el papel que desempeña la imagen corporal en la aprehensión por el sujeto de su «yo»-para Freud, recordemos que el «yo corporal», como aprehensión sensorial de los límites del propio cuerpo, pero también y sobre todo como proyección de una imagen mental de la superficie del cuerpo, es la primera forma del Yo en el sentido psicoanalítico del término; y por ello, el Yo (no tengo tiempo suficiente de demostrarlo aquí) siempre está dotado de género-, o incluso en todo lo que intentamos pensar, desde Hegel hasta Judith Butler pasando por Axel Honneth, en virtud del deseo de reconocimiento y de las condiciones de inteligibilidad -y el género es una de ellas- que permiten la identificación de tal o cual persona, sin la que ningún reconocimiento sería posible. Abandonando el campo de la imagen corporal en beneficio de los pliegues oscuros y otras grutas del cuerpo interior o de las circunvoluciones del anillo libidinal («the libidinal band» en inglés designa la cinta de Moebius lyotardiana), estos textos realizan menos una reducción del cuerpo al sexo -entendamos este como marcador de la división binaria de los seres humanos o, por sinécdoque, como la base imaginaria y simbólica, «especulativa», diría Foucault, de tal o cual identidad social- que una sexualización (a no confundir con la sexuación) de ese cuerpo. Cuando califico este movimiento o este trabajo de queer, me apoyo en una concepción del acto de «queering» próxima a la definición dada por Carla Freccero en Queer Times, cuando habla de «travail de la différance (con una «a») qui viendrait déstabiliser les inflexions identitaires» (485).

En King Kong Théorie, al igual que en sus primeras novelas, Despentes se entrega con insistencia a evidenciar las relaciones que unen insidiosamente diversas formas de discriminación o de humillación, en base a la clase, el género o la raza. Y es innegable que las pensadoras, pensadores y activistas queer (y también las y los que comparten esta línea intelectual y política) son, hoy en día, las y los defensores más sólidos y más constantes de un enfoque

Feminismo/s 34, diciembre 2019, pp. 97-120 
o de un análisis interseccional de la formación de las jerarquías sociales, así como de la imbricación de las formas de dominación. Ahora bien, para lograrlo, Despentes vuelve a atravesar el espejo, donde las imágenes se forman y cuentan, y, con ellas, las «inflexiones identitarias», o «contra-identitarias». El primer enunciado de King Kong Théorie «j'écris de chez les moches»- pone de relieve ya el papel que juega la apariencia física -cómo nos vemos y cómo nos ven los demás- en la imposición del género (en este caso del género femenino), entendido como un ideal (a la vez, literalmente, como una idea y como una imagen) al que deberíamos intentar conformarnos o, al contrario, del que deberíamos escapar en favor del gesto de disidencia subjetiva que la escritura permite (9). El último párrafo de este primer capítulo de King Kong, que se titula, en un interlenguaje 'franglés' que respeta muy poco las fronteras lingüísticas y las reglas de género, «Bad lieutenantes», está totalmente dedicado a la descripción del modelo al que debe parecerse una mujer si desea pasar por una verdadera mujer, identificable, aceptable y por lo tanto consumible como tal, en la sociedad occidental burguesa contemporánea. Debe ser blanca, por supuesto, «séduisante mais pas pute, [...] mince mais pas névrosée par la nourriture, restant indéfiniment jeune sans se faire défigurer par les chirurgiens de l'esthétique [...]» (14) Con ello, Despentes impugna la norma en la que una mujer como tal debería supuestamente encajar, o el ideal impuesto al que debe aspirar, a la vez socialmente y subjetivamente. Pero realmente no trata de romper el encanto (o los perfiles) de la imagen; no cuestiona la primacía de lo que llamamos banalmente la apariencia, como soporte y catalizador de procesos de categorización e idealización, incluso si, como podemos observar, se interesa de manera crítica por el papel de lo que Erving Goffman llamaba la «presentación de sí» en el establecimiento y la consolidación de las identidades sociales (lo que llamamos también, hoy en día, la producción de los estereotipos de género), incluso en la definición de sí mismo, o, más exactamente, del yo. En el último capítulo de King Kong asegura que «elle [s']en tape que le héros porte une jupe et de gros nibards ou qu'il bande comme un cerf et fume le cigare» (155). Tal declaración, que supuestamente ilustra el hecho de que «fuerza» o «valentía», exaltadas en la frase anterior, no tienen ni sexo ni género, adopta casi la forma de versos de mirlitón, en espiral, que podríamos llamar queer, ya que practican una forma de crossing; la oración compuesta de dos casi-alejandrinos hace rimar

Feminismo/s 34, diciembre 2019, pp. 97-120 
nibards - palabra que designa los atributos femeninos pero cuya desinencia sería denominada masculina en versificación clásica, con la palabra cigare, atributo masculino cuya terminación en «e» muda, se considera femenina. Pero, sobre todo, una vez más, Despentes hace intervenir y pone en valor las apariencias, ya se trate de poner de relieve la ropa llevada o la función de los marcadores de género asignada a los diferentes atributos visibles tales como las tetas o el puro. El acento puesto en la exhibición, la fijación del género o sobre el género como fijación, es decir, como manifestación visible de un comportamiento codificado o normativizado, o incluso en la subversión del código en favor de las prácticas del crossing, entra ciertamente más bien en consonancia con la teoría butleriana del género como performance y como cita, o incluso con la problemática del passing en la teoría y la política transgénero, que con la práctica fantasmática de despiece erótico del cuerpo amado en Le corps lesbien de Wittig o el profundo sondeo de cuerpos provistos de soplos de inspiraciones y exhalaciones nuevas en Cixous. Ambas son dos tentativas, sin duda diferentes, de «cargarse» al género con el estilo y con la escritura.

¿Qué es queer, o más queer, hoy en día? ¿La «banda libidinal» - the libidinal band - o la banda de chicas fálicas de Despentes? ¿Desde qué lado del espejo hay que armar la «resistencia», si no la más eficaz, al menos la más radical, a la «homogeneización cultural», no en general, sino con todas las herramientas y las fuerzas de la literatura? ¿De este lado del espejo, donde se forman, se consolidan, se fijan o son subvertidas las imágenes recibidas del cuerpo, o del otro lado del espejo, ahí donde la mirada se pierde y donde ya no hay lados, reversos, anversos, blanco o negro, femenino o masculino que resistan, where sides, sights and sites fail to line up $?^{18}$.

18. Eve Sedgwick Kosofsky, otra gran figura estadounidense del pensamiento queer, define la literatura como una práctica queer, desde el momento en que se esfuerza por interrogar a las formaciones discursivas hegemónicas dando a la lengua un giro extraño, de manera que las inferencias de sentido habituales o incluso los modos de categorización ordinarios se vean trastornados. Son así potencialmente queer «sites where meanings don't line up tidly with each other», literalmente, ámbitos o configuraciones en las cuales los significados producidos no están correctamente alineados los unos con los otros, y donde, como consecuencia, la coherencia, semántica e ideológica, se encuentra amenazada (3). 


\section{REFERENCIAS BIBLIOGRÁFICAS}

Artaud, Antoine. Dossier d'Artaud le Mômo, Oeuvres complètes. Vol. 12. Paris: Gallimard, 1974.

Chaperon, Sylvie. «Haro sur le Deuxième Sexe». En C. Bard, Un Siècle d'anti-féminisme, Paris: Fayard, 1999. 272-275.

Chawaf, Chantal. Cercoeur. Paris: Mercure de France, 1975.

Cixous, Hélène. Souffles. Paris: Éditions des Femmes, 1975.

Cixous, Hélène. Le Rire de la Méduse [1975]. Le Rire de la Méduse et autres ironies. Paris: Galilée, reedición 2010.

Cixous, Hélène y Cathrine Clément. «Sorties». La Jeune Née. Paris: Éditions Bourgois, coll. 10/18, 1975.

Denis, Marie. Les Cahiers du GRIF 9.1 (1975).

Derrida, Jacques. Positions. Paris: Editions de Minuit, 1972.

Derrida, Jacques. Marges De la philosophie. Paris: Minuit, 1972.

Derrida, Jacques. La Vérité en peinture. Paris: Flammarion, 1978.

Derrida, Jacques. Parages. Paris: Galilée, 2003 (nueva edición aumentada).

Despentes, Virginie. King Kong Théorie. Paris: Grasset, 2006.

Forrester, Viviane. Vestiges. Paris: Éditions Seuil, 1978.

Foucault, Michel. Histoire de la sexualité I. La Volonté de Savoir. Paris: Gallimard, coll. Tel, 1976.

Freccero, Carla. «Queer Times». Journal Issue. 106.3 (Summer 2007): 485-495. Hemmings, Clara. «Is Gender Studies Singular? Stories of Queer/Feminist Difference and Displacement». Differences 27.2 (septiembre de 2016): 79-102. Horer, Suzanne y Jeanne Socquet. La Création étouffée. Paris: Éditions Pierre Horay, 1973.

Hyvrard, Jeanne. La Pensée corps. Paris: Éditions des femmes, 1989.

Jones, Ernest. Vida y obra de Sigmund Freud. Vol. 2. Barcelona: Anagrama, «Ed. de Bolsillo», 1981.

Krysinska, Marie. La Force du désir. Paris: Mercure de France, 1905.

Lasserre, Audray. Histoire d'une littérature en mouvement: textes, écrivaines et collectifs éditoriaux du Mouvement de Libération des femmes en France (1970-1981). Paris 3, 2014. <http://theses.fr/2014PA030139>.

Lauretis, Teresa (de). (1991). «Queer Theory: Lesbian and Gay Sexualities». Differences: a Journal of Feminist Cultural Studies, 3.2 (1991): III-XVIII. Leclerc, Annie. Parole de femme. Paris: Grasset, 1974.

Lyotard, Jean-François. Économie libidinale. Paris: Éditions de Minuit, 1974. 
Montrelay, Michèle. L’Ombre et le nom. Sur la féminité. Paris: Éditions de Minuit, 1977.

Rimbaud, Arthur. «Being Beauteous». Illuminations. Paris: La Vogue, 1886.

Saint-Point, Valentine (de). Une femme et le désir. Paris: Léon Vanier, 1910.

Sedgwick Kosofsky, Eve. «Queer and Now». Tendencies (1993): 3.

Segarra, Marta. Traces du désir. Paris: Campagne Première, 2008.

Wittig, Monique. Le corps lesbien. Paris: Minuit, 1973. 